\title{
PENGARUH PELATIHAN DAN PEMBERIAN BONUS TERHADAP MOTIVASI KERJA DAN PRODUKTIVITAS KERJA KARYAWAN DI PT.LAMONGAN INTEGRATED SHOREBASE (LIS)
}

\author{
Titis Tatasari \\ STIE Mahardhika Surabaya
}

\begin{abstract}
ABSTRAK
Pada saat ini faktor-faktor yang mempengaruhi produktifitas sudah dilaksanakan oleh manajemen, tetapi pengaruhnya belum terlihat secara jelas. Dengan adanya penelitian pengaruh pelatihan dan pemberian bonus terhadap motivasi kerja dan produktifitas kerja karyawan di PT. Lamongan Integrated Shorebase (LIS) maka pengaruh terbesar terhadap produktifitas akan tetap dipertahankan sedang yang kurang mempengaruhi akan ditingkatkan lagi sehingga terjadi pengaruh yang cukup signifikan. Tujuan dari penelitian ini adalah : 1) untuk mengetahui dan menguji pengaruh pelatihan terhadap motivasi kerja karyawan PT. Lamongan Integrated Shorebase (LIS), 2) untuk mengetahui dan menguji pengaruh pemberian bonus terhadap motivasi kerja karyawan PT.Lamongan Integrated Shorebase (LIS),3) untuk mengetahui dan menguji pengaruh motivasi kerja terhadap produktifitas kerja karyawan PT. Lamongan Integrated Shorebase (LIS), 4) untuk mengetahui dan menguji pengaruh pelatihan terhadap produktifitas kerja karyawan PT. Lamongan Shorebase (LIS), 5) untuk mengetahui dan menguji pengaruh pemberian bonus terhadap produktifitas kerja karyawan PT. Lamongan Integrated Shorebase (LIS). Berdasarkan pemaparan hasil analisis, penelitian menghasilkan beberapa kesimpulan, yaitu : 1) pelatihan berpengaruh signifikan terhadap motivasi di Lamongan Integrated Shorebase (LIS). Hipotesis ini terbukti bahwa pelatihan memmpunyai pengaruh signifikan terhadap Motivasi, nilainya adalah 0,354. Dengan kata lain, hipotesis pertama $\left(H_{1}\right)$ dierima. Artinya, jika pelatihan terhadap pegawai selalu ditingkatkan, maka hal tersebut sangat berpengaruh terhadap rasa Motivasi karyawan. Begitupun sebaliknya, 2) pemberian bonus berpengaruh signifikan terhadap Motivasi di Lamongan Integrated Shorebase (LIS), 3) pelatihan berpengaruh signifikn terhadap produktifitas kerja karyawan di Lamongan Integrated Shorebase (LIS), 4) pemberian bonus berpengaruh signifikan terhadap produktifitas kerja karyawan di Lamongan Integrated Shorebase (LIS), 5) motivasi berpengaruh signifikan terhadap produktifitas kerja karyawan di Lamongan Integrated Shorebase (LIS).
\end{abstract}

Kata kunci: pelatihan, pemberian bonus, motivasi, produktifitas

\section{PENDAHULUAN}

Pimpinan organisasi pada suatu perusahaan, masalah yang sering dihadapi pimpinan organisasi adalah bagaimana mencari cara yang paling terbaik yang harus ditempuh agar dapat menggerakkan dan meningkatkan produktivitas kerja karyawannya agar secara sadar dan bertanggungjawab melaksanakan tugas dengan sebaik- 
baiknya, karena setiap karyawan mempunyai kebutuhan dan keinginan yang berbeda-beda sehingga pimpinan harus mengerti dan memahami kebutuhan serta keinginan para anggotanya. Karyawan yang ada dalam PT.Lamongan Integrated Shorebase (LIS). Apabila kebutuhan serta keinginan karyawan sudah terpenuhi, maka mereka akan melaksanakan dan pekerjaannya dengan baik serta juga akan lebih bersemangat dalam bekerja sehingga karyawan itu memiliki kesanggupan atas tugas yang dibebankan, kesanggupan untuk bekerja sama serta sanggup menaati peraturan berorganisasi. Manajemen PT. Lamongan Integrated Shorebase (LIS) melakukan analisa mengenai tingkat produktivitas yang akan dihasilkan sehingga pihak manajemen mengadakan pertemuan dan memutuskan untuk mencari faktor yang mempengaruhi motivasi kerja terhadap produktivitas karyawan. Pada saat ini faktor-faktor yang mempengaruhi produktivitas sudah dilaksanakan oleh manajemen, tetapi pengaruhnya belum terlihat secara jelas. Dengan adanya penelitian ini maka pengaruh terbesar terhadap produktifitas akan tetap dipertahankan sedang yang kurang mempengaruhi akan ditingkatkan lagi sehingga terjadi pengaruh yang cukup signifikan.

\subsection{Produktivitas Kerja}

Menurut Sunyoto

"Memahami

Produktivitas"

Produktivitas memang berbeda dengan produksi walaupun hal ini dianggap sama oleh sebagian orang.Produksi adalah suatu kegiatan yang berhubungan dengan hasil keluaran dan umumnya dinyatakan volume produksi dan dalam satuan unit-unit. Disisi lain, produktivitas adalah suatu perbandingan antara besarnya keluaran dengan besarnya masukkan.

\subsection{Motivasi Kerja}

Menurut Uno,HB (2010:1) motivasi adalah dorongan dasar yang menggerakkan seseorang bertingkah laku. Dorongan ini berada pada diri seseorang yang menggerakkan untuk melakukan sesuatu yang sesuai dengan dorongan dari dalam dirinya.

\subsection{Pelatihan}

Menurut Siagian (2012) pelatihan adalah proses belajar mengajar dengan menggunakan tehnik dan metoda tertentu secara konsepsional dapat dikatakan bahwa latihan dimaksudkan untuk meningkatkan keterampilan dan kemampuan kerja seseorang atau sekelompok orang. Biasanya yang sudah 
bekkerja pada suatu organisasi yang efisien, efektivitas dan produktivitas kerjanya dirasakan perlu untuk dapat ditingkatkan secara terarah dan pragmatik.

\subsection{Pengaruh Motivasi Kerja terhadap Produktivitas Kerja}

Produktivitas merupakan suatu aspek yang penting bagi perusahaan karena apabila tenaga kerjadalam perusahaan mempunyai kerja yang tinggi maka perusahaan akan memperoleh keuntungan dan hidup perusahaan akan terjamin. Untuk meningkatkan produktivitas kerja perlu adanya tenaga kerja yang memiliki keterampilan dan keahlian kerja, karena apabila tenaga kerja tidak memiliki keahlian dan keterampilan akan berakibat menurunnya produktivitas dan merugikan perusahaan. Produktivitas dipengaruhi beberapa faktor baik yang berhubungan dengan tenaga kerja itu sendiri maupun faktor-faktor lainnya seperti pendidikan, keterampilan, disiplin kerja, sikap, etika, manajemen,motivasi kerja, teknologi, sarana, produksi, kesempatan kerja dan kesempatan berprestasi serta lingkungan kerja yang mendukung (Alim,2007).

\section{METODE PENELITIAN}

Penelitian ini menggunakan penelitian penjelasan (explanative research) karena penelitian ini bermaksud untuk menjelaskan hubungan kausal (sebab akibat) antar veriabel melalui pengujian hipotesis yang telah dirumuskan. Kegiatan penelitian ini dilakukan di PT. Lamongan Integrated Shorebase (LIS) yang berada di Kecamatan Paciran Kabupaten Lamongan. Ruang lingkup penelitian ini difokukan pada pelatihan, pemberian bonus, motivasi dan produktivitas kerja karywan PT. Lamongan Integrated Shorebase (LIS) dengan obyek yang diteliti adalah seluruh karyawan di PT. Lamongan Integrated Shorebase (LIS). Teknik analisis data menggunakan path analysis (analisa jalur) untuk mengetahui bagaimana pengaruh motivasi dan pemberian bonus terhadap motivasi kerja dan produktivitas kerja karyawan baik secara langsung maupun tidak langsung.

\section{ANALISIS DAN PEMBAHASAN \\ Alat analisis yang digunakan pada penelitian ini analisis jalur atau path analysis dengan program AMOS dengan uji yang digunakan adalah uji t (C.R) apabila hasil perhitungan dengan modal tersebut nilainya adalah lebih besar dari}


2 atau $\mathrm{P} \leq 0,05$ maka hubungan antara variabel satu dengan variabel lain hubungannya signifikan, selebihnya apabila nilainya $\mathrm{P}$ lebih tinggi dari 0,05 maka hubungannya tidak signifikan.

Tabel 1. Hubungan Variabel Bebas Terhadap Variabel Antara Dan Variabel Tidak Bebas

\begin{tabular}{|c|l|c|c|c|c|c|}
\hline No & Variabel Bebas & $\begin{array}{c}\text { Variabel } \\
\text { Tidak Bebas }\end{array}$ & $\begin{array}{c}\text { Koefisien } \\
\text { Jalur }\end{array}$ & C.R & Prob. & Ket. \\
\hline 1 & Pelatihan & Motivasi & 0,354 & 3,53 & 0,024 & $\mathrm{~S}$ \\
\hline 2 & $\begin{array}{l}\text { Pemberian } \\
\text { Bonus }\end{array}$ & Motivasi & 0,362 & 3,496 & 0,000 & $\mathrm{~S}$ \\
\hline 3 & Pelatihan & Kinerja & 0,371 & 3,748 & 0,038 & $\mathrm{~S}$ \\
\hline 4 & $\begin{array}{l}\text { Pemberian } \\
\text { Bonus }\end{array}$ & Kinerja & 0,456 & 0,456 & 0,000 & $\mathrm{~S}$ \\
\hline 5 & Motivasi & Kinerja & 0,535 & 0,535 & 0,000 & $\mathrm{~S}$ \\
\hline
\end{tabular}

\section{Sumber : Data diolah}

Keterangan : $\mathbf{S}=$ Signifikan

\section{TS = Tidak Signifikan}

Hasil analisis yang dimuat pada Tabel 1 tersebut dapat diketahui :1) Hipotesis pertama, yaitu pelatihan berpengaruh signifikan terhadap motivasi di Lamongan Integrated Shorebase (LIS). Hipotesis ini terbukti bahwa Pelatihan mempunyai pengaruh signifikan dengan motivasi nilainya adalah 0,354 ; 2) Hipotesis kedua, yaitu pemberian bonus berpengaruh signifikan terhadap motivasi di Lamongan Integrated Shorebase (LIS). Hipotesis ini terbukti bahwa pemberian bonus mempunyai pengaruh signifikan dengan motivasi nilainya adalah 0,$362 ; 3$ ) Hipotesis ketiga, yaitu pelatihan berpengaruh signifikan terhadap produktivitas kerja di Lamongan Integrated Shorebase (LIS). Hipotesis ini terbukti bahwa pelatihan mempunyai pengaruh signifikan dengan produktivitas kerja, nilainya adalah 0,371; 4) Hipotesis keempat, yaitu pemberian bonus berpengaruh signifikan terhadap produktivitas kerja di Lamongan Integrated Shorebase (LIS).Hipotesis ini terbukti bahwa pemberian bonus mempunyai pengaruh 
0,456; 5) Hipotesis kelima, yaitu melihat tata hubung tersebut dapat motivasi berpengaruh signifikan diketahui dengan jelas variabel mana terhadap produktivitas kerja di yang berpengaruh signifikan dan Lamongan Integrated Shorebase (LIS). variabel mana yang tidak berpengaruh. Hipotesis ini terbukti bahwa motivasi Tata hubung tiga variabel bebas terhadap mempunyai pengaruh signifikan dengan variabel tidak bebas digambarkan pada produktivitas kerjanya, nilainya 0,535 . Gambar 1.

Hasil analisis terlebih dahulu dibuat tata hubung antar variabel.Dengan

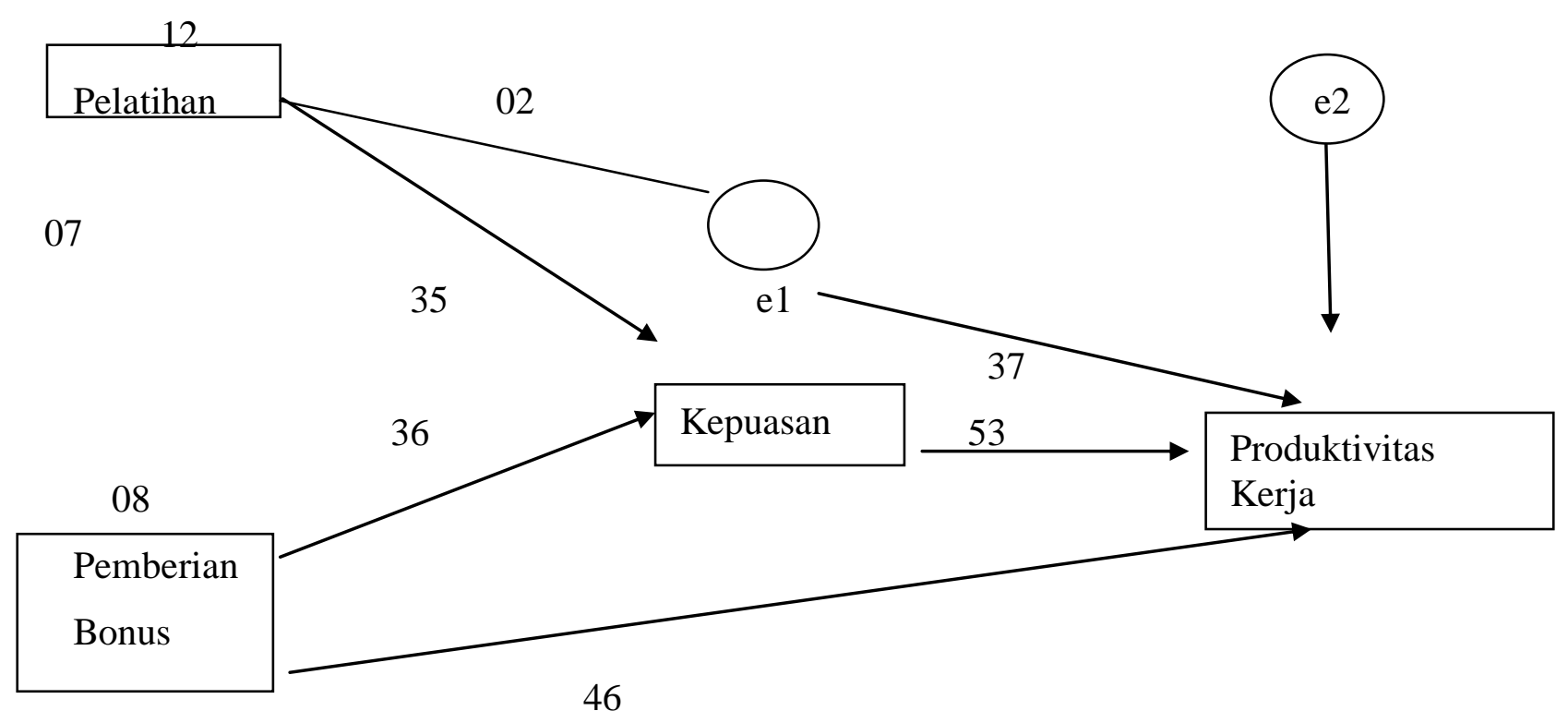

GOODNESS OF FIT

Chi Square $=31.564$

Probability $=.000$

RMSEA $=.409$

Gambar 1. Hasil Path Analisis

Dalam pengujian analisis jalur tentu dilakukan pengujian hipotesis yang telah diajukan sebelumnya. Penggunaanya dilakukan melalui penyaringan uji statistik yang berarti menggunakan koefisien arah beta berdasarkan data dalam bentuk skor baku karena dapat dibuktikan dan jika beta signifikan maka koefisien jalur akan signifikan pula pada Gambar 1. Menunjukkan bahwa dari 
tujuh hipotesis yang dikemukakan, semuanya memiliki pengaruh langsung dan signifikan, hal ini memberikan indikasi bahwa 1) pelatihan, dan pemberian bonus berpengaruh terhadap Motivasi pegawai di Lamongan Integrated Shorebase (LIS) dan 2) pelatihan, pemberian bonus dan motivasi berpengaruh terhadap produktivitas kerja di Lamongan Integrated Shorebase (LIS). Hal ini didukung dari Gambar 1 terlihat bahwa nilai error atau indicator lain (d1,d2,e1, dan e2) selain dari model yang ditentukan dalam penelitian ini nilainya kecil, artiya nilai error pelatihan (d1) 0,12 , nilai error pemberian bonus (d2) 0,08, nilai error motivasi (e1) 0,02 dan nilai error kinerja (e3) 0,07 tersebut tidak ada hubungannya, karena nilainya semua dibawah 0,164. Untuk mengetahui nilai hubungan lemah atau kuat dalam analisis path, Sumarno (2012) berpendapat dalam Tabel 2.

Tabel 2. Nilai Path Analisis

\begin{tabular}{|c|l|l|}
\hline No & \multicolumn{1}{|c|}{ Nilai } & \multicolumn{1}{|c|}{ Hubungan } \\
\hline 1 & $0-0164$ & $\begin{array}{l}\text { Tidak ada } \\
\text { hubungan }\end{array}$ \\
\hline 2 & $0,165-0,335$ & Lemah \\
\hline 3 & $\begin{array}{l}0,335 \\
\text { keatas }\end{array}$ & Kuat \\
\hline
\end{tabular}

\subsection{Pelatihan beperngaruh terhadap motivasi}

Hasil uji ini menunjukkan pelatihan mempunyai hubungan signifikan dengan Motivasi. Uji analisis jalur dari variabel pelatihan (X1) ke varibael motivasi (Y1) menghasilkan nilai koefisien sebesar 0,354 hal ini menunjukkan bahwa hubungan antara pelatihan dan motivasi adalah kuat, karena nilainya diatas 0,335 dan $\mathrm{t}$ (CR) sebasar 3,754 serta probabilitasnya atau $\mathrm{P} \leq 0,05$ maka hubungan variabel pelatihan dengan variabel motivasi adalah signifikan. Hal ini dapat diartikan responden menganggap motivasi yang terjadi pada mereka dikarenakan oleh pelatihan. Artinya, apabila pelatihan para karyawan di Lamongan Integrated Shorebase (LIS) variabeditingkatkan maka juga akan mempunyai hubungan pada tingkat motivasi.

\subsection{Pemberian bonus berpengaruh terhadap motivasi}

Uji analisis jalur dari variabel pemberian bonus (X2) ke variabel motivasi (Y1) menghasilkan nilai koefisien sebesar 0,362, hal ini menunjukkan bahwa hubungan antara pemberian bonus dengan motivasi adalah kuat, karena nilainya diatas 0,335 dan $\mathrm{t}$ (CR) sebesar 3,496 serta 
probabilitasnya 0,000 . Hasil perhitungan dengan model tersebut nilainya $\mathrm{CR}$ adalah lebih besar dari 2 dan nilai probabilitasnya atau $\mathrm{P} \leq 0,05$ maka hubungan variabel pemberian bonus dengan variabel motivasi adalah signifikan. Hal ini dapat diartikan responden menganggap motivasi yang terjadi pada mereka dikarenakan oleh pemberian bonus. Artinya, apabila pemberian bonus para pegawai di Lamongan Integrated Shorebase (LIS) ditingkatkan maka juga akan mempunyai pengaruh pada tingkat motivasi mereka.

\subsection{Pelatihan berpengaruh terhadap} produktivitas kerja

Uji analisis jalur dari variabel pelatihan (X1) ke variabel produktivitas kerja (Y2) menghasilkan nilai koefisien sebesar 0,371 hal ini menunjukkan bahwa hubungan antara pelatihan dengan kinerja adalah kuat, karena nilainya diatas 0,335 dan $\mathrm{t}(\mathrm{CR})$ sebesar 3,748 serta probabilitasnya 0,038 hasil perhitungan dengan model tersebut nilainya $\mathrm{CR}$ adalah lebih besar dari 2 dan nilai probabilitasnya atau $\mathrm{P} \leq 0,05$ maka hubungan variabel pelatihan dengan variabel produktivitas kerja adalah signifikan. Hal ini dapat diartikan responden menganggap produktivitas kerja yang terjadi pada mereka dikarenakan oleh pelatihan. Artinya, apabila pelatihan para karyawan di Lamongan Integrated Shorebase (LIS) ditingkatkan maka juga akan mempunyai hubungan pada tingkat produktivitas mereka dalam bekerja.

\subsection{Pemberian Bonus berpengaruh terhadap produktivitas kerja}

Uji analisis jalur dari variabel pemberian bonus (X2) ke variabel produktivitas kerja (Y2) menghasilkan nilai koefisien sebesar 0,456 hal ini menunjukkan bahwa hubungan antara pemberian bonus dengan produktivitas kerja adalah kuat, karena nilainya diatas 0,335 dan $\mathrm{t}$ (CR) sebesar 4,389 serta probabilitasnya 0,000 . Hasil perhitungan dengan model tersebut nilainya $\mathrm{CR}$ adalah lebih besar dari 2 dan nilai probabilitasnya atau $\mathrm{P} \leq 0,05$ maka hubungan variabel pemberian bonus dengan variabel produktivitas kerja adalah signifikan. Hal ini dapat diartikan responden menganggap peningkatan produktivitas kerja yang terjadi pada mereka dikarenakan oleh adanya pemberian bonus. Maksudnya apabila pemberian bonus pada karyawan di Lamongan Integrated Shorebase (LIS) ditingkatkan maka juga akan mempunyai hubungan dengan produktivitas mereka dalam bekerja. 


\subsection{Motivasi beperngaruh terhadap produktivitas kerja}

Uji analisis jalur variabel motivasi (Y1) ke variabel produktifitas kerja (Y2) menghasilkan nilai koefisien sebesar 0,535. Hal ini menunjukkan bahwa hubungan antara motivasi dengan produktivitas kerja adalah kuat, karena nilainya di atas 0,335 dan $\mathrm{t}(\mathrm{CR})$ sebesar 6,156 serta probabilitasnya 0,000 . Hasil perhitungan dengan model tersebut nilainya $\mathrm{CR}$ adalah lebih besar dari 2 dan nilai probabilitasnya atau $\mathrm{P} \leq 0,05$, maka hubungan variabel motivasi dengan variabel produktivitas kerja yang terjadi pada mereka dikarenakan oleh motivasi (Y1).

\section{SIMPULAN}

Berdasarkan penelitian dari hasil analisis menghasilkan beberapa kesimpulan : 1) pelatihan berpengaruh signifikan terhadap motivasi di Lamongan Integrated Shorebase (LIS). Hipotesis ini terbukti bahwa pelatihan mempunyai pengaruh signifikan terhadap motivasi, nilainya adalah 0,354 . Dengan kata lain, hipotesis pertama $\left(\mathrm{H}_{1}\right)$ diterima, Artinya jika pelatihan terhadap pegawai selalu ditingkatkan maka hal tersebut sangat berpengaruh terhadap rasa motivasi karyawan. Begitupun sebaliknya.

Pemberian bonus berpengaruh signifikan terhadap motivasi di Lamongan Integrated Shorebase (LIS). Hipotesis ini terbukti bahwa pemberian bonus mempunyai pengaruh signifikan dengan motivasi, nilainya adalah 0,362 . Dengan kata lain, hiptesis kedua $\left(\mathrm{H}_{2}\right)$ diterima. Artinya jika pemberian bonus ditingkatkan, akan membawa pengaruh terhadap motivasi karyawan. Begitupun sebaliknya. Pelatihan berpengaruh signifikan terhadap produktivitas kerja karyawan di Lamongan Integrated Shorebase (LIS). Hipotesis ini terbukti bahwa pelatihan mempunyai pengaruh signifikan dengan produktivitas kerja karyawan, nilainya adalah 0,371. Dengan kata lain hipotesis ketiga $\left(\mathrm{H}_{3}\right)$ diterima. Artinya jika pelatihan selalu diberikan juga berpengaruh pada produktivitas kerja karyawan. Begitupun sebaliknya.

Pemberian bonus berpengaruh signifikan terhadap produktivitas kerja karyawan di Lamongan Integrated Shorebase (LIS). Hipotesis ini terbukti bahwa pemberian bonus mempunyai pengaruh signifikan dengan produktivitas kerja karyawan, nilainya adalah 0,456. Dengan kata lain, hipotesis 
keempat $\left(\mathrm{H}_{4}\right)$ diterima. Artinya jika pemberian bonus ditingkatkan akan berpengaruh positif terhadap produktivitas kerja karyawan. Begitupun sebaliknya. Motivasi berpengaruh signifikan terhadap produktivitas kerja karyawan di Lamogan Integrated Shorebase (LIS). Hipotesis ini terbukti bahwa motivasi mempunyai pengaruh signifikan dengan produktivitas kerja karyawan, nilainya adalah 0,535. Hipotesis kelima $\left(\mathrm{H}_{5}\right)$ juga diterima. Artinya, jika pegawai mendapatkan motivasi secara tidak langsung berpengaruh terhadap produktivitas kerja karyawan. Begitupun sebaliknya.

\section{DAFTAR PUSTAKA}

Alim,Sumarno.2012.Penelitian

Kausalitas Komparatif. Surabaya : elearning unesa

Alim,M.N.,T.Hapsari.,L.Purwanti.2007.

Pengaruh Kompetensi dan Independent terhadap kualitas Audit dengan Etika Auditor sebagai Variabel Moderasi. Simposium Nasional Akuntansi X 26-28 Juli Makasar.

Siagian.2012. Manajemen Sumber Daya Manusia. Jakarta : Bumi Aksara
Sunyoto.2012.Manajamen Sumber Daya Manusia. Yogyakarta : CAPS

Uno, HB.2010. Teori Motivasi dan Pengukurannya : Analisis di Bidang Pendidikan. Jakarta : Bumi Aksara 